\title{
Social Media and Fake News in the 2016 Election
}

\section{Hunt Allcott and Matthew Gentzkow}

A merican democracy has been repeatedly buffeted by changes in media technology. In the 19th century, cheap newsprint and improved presses allowed partisan newspapers to expand their reach dramatically. Many have argued that the effectiveness of the press as a check on power was significantly compromised as a result (for example, Kaplan 2002). In the 20th century, as radio and then television became dominant, observers worried that these new platforms would reduce substantive policy debates to sound bites, privilege charismatic or "telegenic" candidates over those who might have more ability to lead but are less polished, and concentrate power in the hands of a few large corporations (Lang and Lang 2002; Bagdikian 1983). In the early 2000s, the growth of online news prompted a new set of concerns, among them that excess diversity of viewpoints would make it easier for like-minded citizens to form "echo chambers" or "filter bubbles" where they would be insulated from contrary perspectives (Sunstein 2001a, b, 2007; Pariser 2011). Most recently, the focus of concern has shifted to social media. Social media platforms such as Facebook have a dramatically different structure than previous media technologies. Content can be relayed among users with no significant third party filtering, fact-checking, or editorial judgment. An individual user with no track record or reputation can in some cases reach as many readers as Fox News, CNN, or the New York Times.

- Hunt Allcott is Associate Professor of Economics, New York University, New York City, New York. Matthew Gentzkow is Professor of Economics, Stanford University, Stanford, California. Both authors are Research Associates, National Bureau of Economic Research, Cambridge, Massachusetts.

${ }^{\dagger}$ For supplementary materials such as appendices, datasets, and author disclosure statements, see the article page at 
Following the 2016 election, a specific concern has been the effect of false stories- "fake news," as it has been dubbed-circulated on social media. Recent evidence shows that: 1) 62 percent of US adults get news on social media (Gottfried and Shearer 2016); 2) the most popular fake news stories were more widely shared on Facebook than the most popular mainstream news stories (Silverman 2016); 3) many people who see fake news stories report that they believe them (Silverman and Singer-Vine 2016); and 4) the most discussed fake news stories tended to favor Donald Trump over Hillary Clinton (Silverman 2016). Putting these facts together, a number of commentators have suggested that Donald Trump would not have been elected president were it not for the influence of fake news (for examples, see Parkinson 2016; Read 2016; Dewey 2016).

Our goal in this paper is to offer theoretical and empirical background to frame this debate. We begin by discussing the economics of fake news. We sketch a model of media markets in which firms gather and sell signals of a true state of the world to consumers who benefit from inferring that state. We conceptualize fake news as distorted signals uncorrelated with the truth. Fake news arises in equilibrium because it is cheaper to provide than precise signals, because consumers cannot costlessly infer accuracy, and because consumers may enjoy partisan news. Fake news may generate utility for some consumers, but it also imposes private and social costs by making it more difficult for consumers to infer the true state of the world-for example, by making it more difficult for voters to infer which electoral candidate they prefer.

We then present new data on the consumption of fake news prior to the election. We draw on web browsing data, a new 1,200-person post-election online survey, and a database of 156 election-related news stories that were categorized as false by leading fact-checking websites in the three months before the election.

First, we discuss the importance of social media relative to sources of political news and information. Referrals from social media accounted for a small share of traffic on mainstream news sites, but a much larger share for fake news sites. Trust in information accessed through social media is lower than trust in traditional outlets. In our survey, only 14 percent of American adults viewed social media as their "most important" source of election news.

Second, we confirm that fake news was both widely shared and heavily tilted in favor of Donald Trump. Our database contains 115 pro-Trump fake stories that were shared on Facebook a total of 30 million times, and 41 pro-Clinton fake stories shared a total of 7.6 million times.

Third, we provide several benchmarks of the rate at which voters were exposed to fake news. The upper end of previously reported statistics for the ratio of page visits to shares of stories on social media would suggest that the 38 million shares of fake news in our database translates into 760 million instances of a user clicking through and reading a fake news story, or about three stories read per American adult. A list of fake news websites, on which just over half of articles appear to be false, received 159 million visits during the month of the election, or 0.64 per US adult. In our post-election survey, about 15 percent of respondents recalled seeing each of 14 
major pre-election fake news headlines, but about 14 percent also recalled seeing a set of placebo fake news headlines-untrue headlines that we invented and that never actually circulated. Using the difference between fake news headlines and placebo headlines as a measure of true recall and projecting this to the universe of fake news articles in our database, we estimate that the average adult saw and remembered 1.14 fake stories. Taken together, these estimates suggest that the average US adult might have seen perhaps one or several news stories in the months before the election.

Fourth, we study inference about true versus false news headlines in our survey data. Education, age, and total media consumption are strongly associated with more accurate beliefs about whether headlines are true or false. Democrats and Republicans are both about 15 percent more likely to believe ideologically aligned headlines, and this ideologically aligned inference is substantially stronger for people with ideologically segregated social media networks.

We conclude by discussing the possible impacts of fake news on voting patterns in the 2016 election and potential steps that could be taken to reduce any negative impacts of fake news. Although the term "fake news" has been popularized only recently, this and other related topics have been extensively covered by academic literatures in economics, psychology, political science, and computer science. See Flynn, Nyhan, and Reifler (2017) for a recent overview of political misperceptions. In addition to the articles we cite below, there are large literatures on how new information affects political beliefs (for example, Berinsky 2017; DiFonzo and Bordia 2007; Taber and Lodge 2006; Nyhan, Reifler, and Ubel 2013; Nyhan, Reifler, Richey, and Freed 2014), how rumors propagate (for example, Friggeri, Adamic, Eckles, and Cheng 2014), effects of media exposure (for example, Bartels 1993, DellaVigna and Kaplan 2007, Enikolopov, Petrova, and Zhuravskaya 2011, Gerber and Green 2000, Gerber, Gimpel, Green, and Shaw 2011, Huber and Arceneaux 2007, Martin and Yurukoglu 2014, and Spenkuch and Toniatti 2016; and for overviews, DellaVigna and Gentzkow 2010, and Napoli 2014), and ideological segregation in news consumption (for example, Bakshy, Messing, and Adamic 2015; Gentzkow and Shapiro 2011; Flaxman, Goel, and Rao 2016).

\section{Background: The Market for Fake News}

\section{Definition and History}

We define "fake news" to be news articles that are intentionally and verifiably false, and could mislead readers. We focus on fake news articles that have political implications, with special attention to the 2016 US presidential elections. Our definition includes intentionally fabricated news articles, such as a widely shared article from the now-defunct website denverguardian.com with the headline, "FBI agent suspected in Hillary email leaks found dead in apparent murder-suicide." It also includes many articles that originate on satirical websites but could be misunderstood as factual, especially when viewed in isolation on Twitter or Facebook feeds. For example, in July 2016, the now-defunct website wtoe5news.com reported that 
Pope Francis had endorsed Donald Trump's presidential candidacy. The WTOE 5 News "About" page disclosed that it is "a fantasy news website. Most articles on wtoe5news.com are satire or pure fantasy," but this disclaimer was not included in the article. The story was shared more than one million times on Facebook, and some people in our survey described below reported believing the headline.

Our definition rules out several close cousins of fake news: 1) unintentional reporting mistakes, such as a recent incorrect report that Donald Trump had removed a bust of Martin Luther King Jr. from the Oval Office in the White House; 2) rumors that do not originate from a particular news article; ${ }^{[}$3) conspiracy theories (these are, by definition, difficult to verify as true or false, and they are typically originated by people who believe them to be true);24) satire that is unlikely to be misconstrued as factual; 5) false statements by politicians; and 6) reports that are slanted or misleading but not outright false (in the language of Gentzkow, Shapiro, and Stone 2016, fake news is "distortion," not "filtering").

Fake news and its cousins are not new. One historical example is the "Great Moon Hoax" of 1835, in which the New York Sun published a series of articles about the discovery of life on the moon. A more recent example is the 2006 "Flemish Secession Hoax," in which a Belgian public television station reported that the Flemish parliament had declared independence from Belgium, a report that a large number of viewers misunderstood as true. Supermarket tabloids such as the National Enquirer and the Weekly World News have long trafficked in a mix of partially true and outright false stories.

Figure 1 lists 12 conspiracy theories with political implications that have circulated over the past half-century. Using polling data compiled by the American Enterprise Institute (2013), this figure plots the share of people who believed each statement is true, from polls conducted in the listed year. For example, substantial minorities of Americans believed at various times that Franklin Roosevelt had prior knowledge of the Pearl Harbor bombing, that Lyndon Johnson was involved in the Kennedy assassination, that the US government actively participated in the 9/11 bombings, and that Barack Obama was born in another country.

The long history of fake news notwithstanding, there are several reasons to think that fake news is of growing importance. First, barriers to entry in the media industry have dropped precipitously, both because it is now easy to set up websites and because it is easy to monetize web content through advertising platforms. Because reputational concerns discourage mass media outlets from knowingly reporting false stories, higher entry barriers limit false reporting. Second, as we discuss below, social media are well-suited for fake news dissemination, and social

\footnotetext{
${ }^{1}$ Sunstein (2007) defines rumors as "claims of fact-about people, groups, events, and institutions-that have not been shown to be true, but that move from one person to another, and hence have credibility not because direct evidence is available to support them, but because other people seem to believe them."

${ }^{2}$ Keeley (1999) defines a conspiracy theory as "a proposed explanation of some historical event (or events) in terms of the significant causal agency of a relatively small group of persons-the conspirators-acting in secret."
} 


\section{Figure 1}

\section{Share of Americans Believing Historical Partisan Conspiracy Theories}

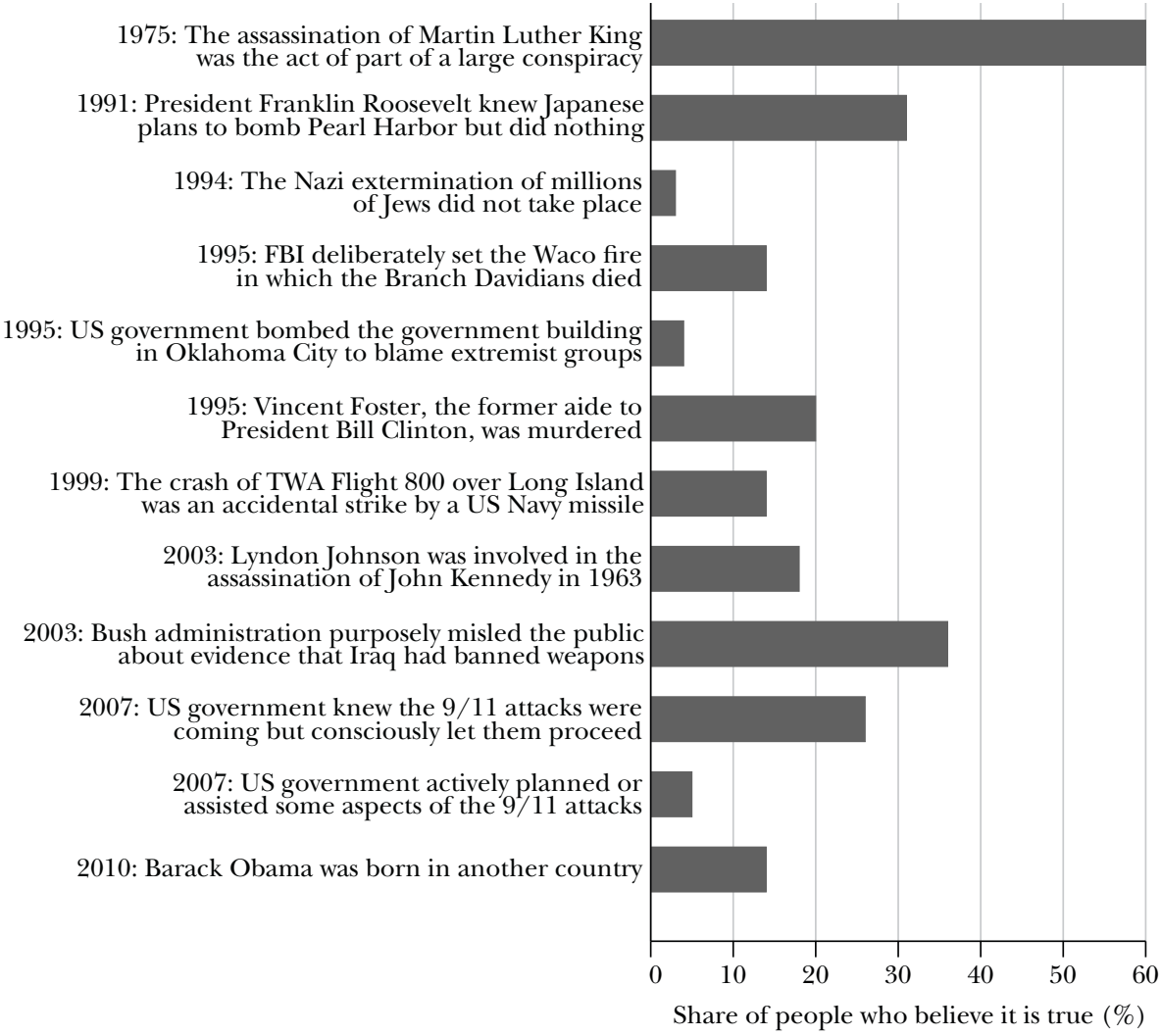

Note: From polling data compiled by the American Enterprise Institute (2013), we selected all conspiracy theories with political implications. This figure plots the share of people who report believing the statement listed, using opinion polls from the date listed.

media use has risen sharply: in 2016, active Facebook users per month reached 1.8 billion and Twitter's approached 400 million. Third, as shown in Figure 2A, Gallup polls reveal a continuing decline of "trust and confidence" in the mass media "when it comes to reporting the news fully, accurately, and fairly." This decline is more marked among Republicans than Democrats, and there is a particularly sharp drop among Republicans in 2016. The declining trust in mainstream media could be both a cause and a consequence of fake news gaining more traction. Fourth, Figure 2B shows one measure of the rise of political polarization: the increasingly negative feelings each side of the political spectrum holds toward the other. ${ }^{3}$ As we

\footnotetext{
${ }^{3}$ The extent to which polarization of voters has increased, along with the extent to which it has been driven by shifts in attitudes on the right or the left or both, are widely debated topics. See Abramowitz and Saunders (2008), Fiorina and Abrams (2008), Prior (2013), and Lelkes (2016) for reviews.
} 
Figure 2

\section{Trends Related to Fake News}

A: Trust in Mainstream Media

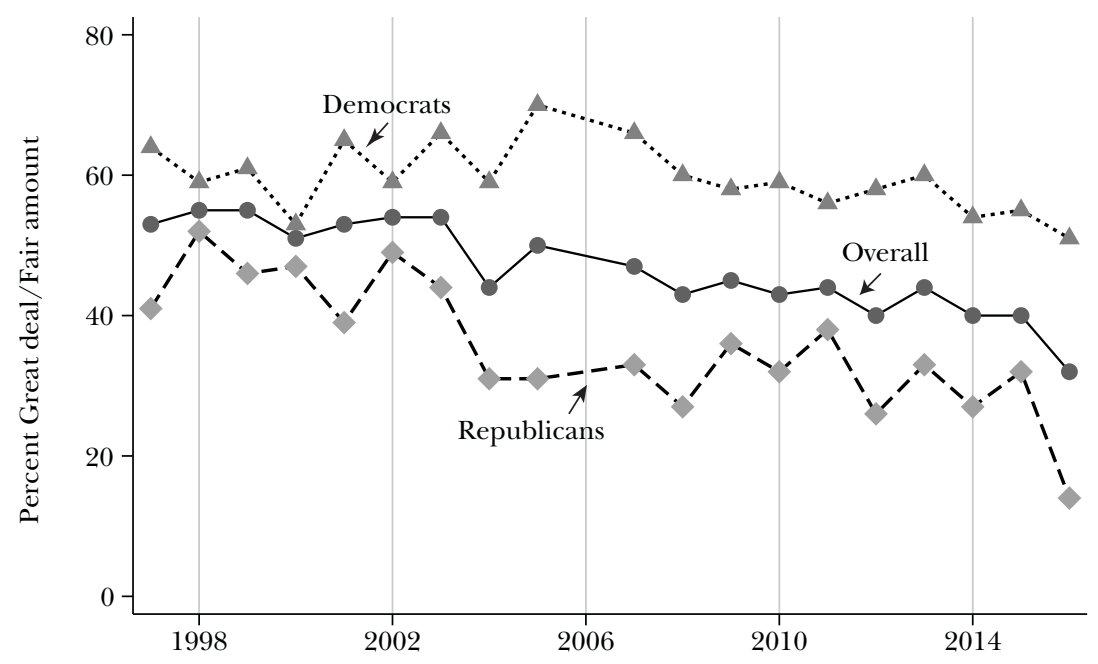

B: Feeling Thermometer toward Other Political Party

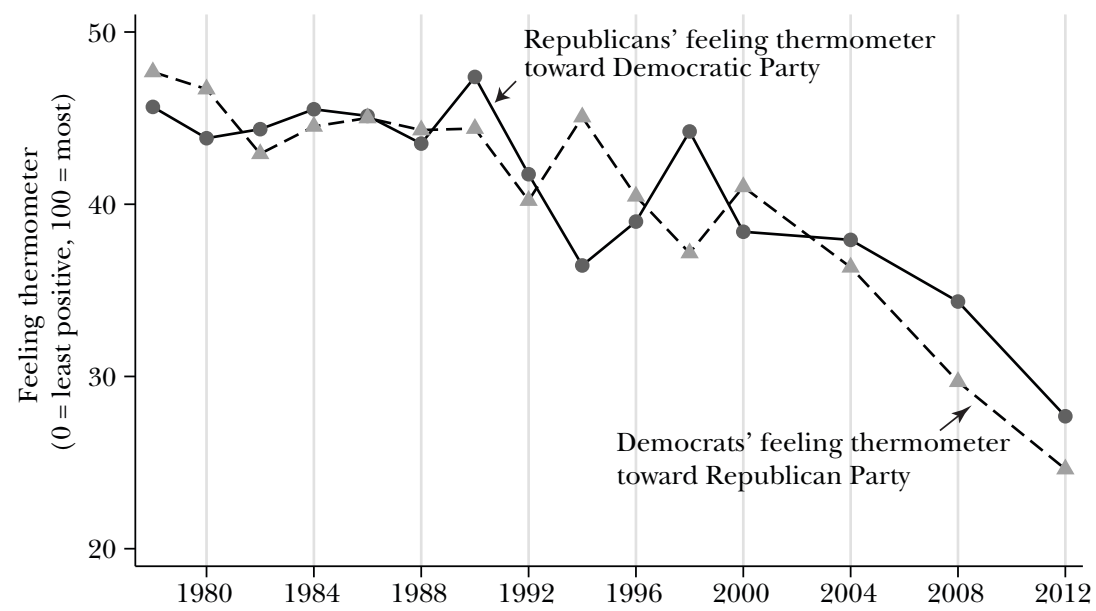

Note: Panel A shows the percent of Americans who say that they have "a great deal" or "a fair amount" of "trust and confidence" in the mass media "when it comes to reporting the news fully, accurately, and fairly," using Gallup poll data reported in Swift (2016). Panel B shows the average "feeling thermometer" (with 100 meaning "very warm or favorable feeling" and 0 meaning "very cold or unfavorable feeling") of Republicans toward the Democratic Party and of Democrats toward the Republican Party, using data from the American National Election Studies (2012). 
discuss below, this could affect how likely each side is to believe negative fake news stories about the other.

\section{Who Produces Fake News?}

Fake news articles originate on several types of websites. For example, some sites are established entirely to print intentionally fabricated and misleading articles, such as the above example of denverguardian.com. The names of these sites are often chosen to resemble those of legitimate news organizations. Other satirical sites contain articles that might be interpreted as factual when seen out of context, such as the above example of wtoe5news.com. Still other sites, such as endingthefed.com, print a mix between factual articles, often with a partisan slant, along with some false articles. Websites supplying fake news tend to be short-lived, and many that were important in the run-up to the 2016 election no longer exist.

Anecdotal reports that have emerged following the 2016 election provide a partial picture of the providers behind these sites. Separate investigations by BuzzFeed and the Guardian revealed that more than 100 sites posting fake news were run by teenagers in the small town of Veles, Macedonia (Subramanian 2017). Endingthefed.com, a site that was responsible for four of the ten most popular fake news stories on Facebook, was run by a 24-year-old Romanian man (Townsend 2016). A US company called Disinfomedia owns many fake news sites, including NationalReport.net, USAToday.com.co, and WashingtonPost.com.co, and its owner claims to employ between 20 and 25 writers (Sydell 2016). Another US-based producer, Paul Horner, ran a successful fake news site called National Report for years prior to the election (Dewey 2014). Among his most-circulated stories was a 2013 report that President Obama used his own money to keep open a Muslim museum during the federal government shutdown. During the election, Horner produced a large number of mainly pro-Trump stories (Dewey 2016).

There appear to be two main motivations for providing fake news. The first is pecuniary: news articles that go viral on social media can draw significant advertising revenue when users click to the original site. This appears to have been the main motivation for most of the producers whose identities have been revealed. The teenagers in Veles, for example, produced stories favoring both Trump and Clinton that earned them tens of thousands of dollars (Subramanian 2017). Paul Horner produced pro-Trump stories for profit, despite claiming to be personally opposed to Trump (Dewey 2016). The second motivation is ideological. Some fake news providers seek to advance candidates they favor. The Romanian man who ran endingthefed. com, for example, claims that he started the site mainly to help Donald Trump's campaign (Townsend 2016). Other providers of right-wing fake news actually say they identify as left-wing and wanted to embarrass those on the right by showing that they would credulously circulate false stories (Dewey 2016; Sydell 2016).

\section{A Model of Fake News}

How is fake news different from biased or slanted media more broadly? Is it an innocuous form of entertainment, like fictional films or novels? Or does it 
have larger social costs? To answer these questions, we sketch a model of supply and demand for news loosely based on a model developed formally in Gentzkow, Shapiro, and Stone (2016).

There are two possible unobserved states of the world, which could represent whether a left- or right-leaning candidate will perform better in office. Media firms receive signals that are informative about the true state, and they may differ in the precision of these signals. We can also imagine that firms can make costly investments to increase the accuracy of these signals. Each firm has a reporting strategy that maps from the signals it receives to the news reports that it publishes. Firms can either decide to report signals truthfully, or alternatively to add bias to reports.

Consumers are endowed with heterogeneous priors about the state of the world. Liberal consumers' priors hold that the left-leaning candidate will perform better in office, while conservative consumers' priors hold that the right-leaning candidate will perform better. Consumers receive utility through two channels. First, they want to know the truth. In our model, consumers must choose an action, which could represent advocating or voting for a candidate, and they receive private benefits if they choose the candidate they would prefer if they were fully informed. Second, consumers may derive psychological utility from seeing reports that are consistent with their priors. Consumers choose the firms from which they will consume news in order to maximize their own expected utility. They then use the content of the news reports they have consumed to form a posterior about the state of the world. Thus, consumers face a tradeoff: they have a private incentive to consume precise and unbiased news, but they also receive psychological utility from confirmatory news.

After consumers choose their actions, they may receive additional feedback about the true state of the world-for example, as a candidate's performance is observed while in office. Consumers then update their beliefs about the quality of media firms and choose which to consume in future periods. The profits of media firms increase in their number of consumers due to advertising revenue, and media firms have an incentive to build a reputation for delivering high levels of utility to consumers. There are also positive social externalities if consumers choose the higher-quality candidate.

In this model, two distinct incentives may lead firms to distort their reports in the direction of consumers' priors. First, when feedback about the true state is limited, rational consumers will judge a firm to be higher quality when its reports are closer to the consumers' priors (Gentzkow and Shapiro 2006). Second, consumers may prefer reports that confirm their priors due to psychological utility (Mullainathan and Shleifer 2005). Gentzkow, Shapiro, and Stone (2016) show how these incentives can lead to biased reporting in equilibrium, and apply variants of this model to understand outcomes in traditional "mainstream" media.

How would we understand fake news in the context of such a model? Producers of fake news are firms with two distinguishing characteristics. First, they make no investment in accurate reporting, so their underlying signals are uncorrelated with the true state. Second, they do not attempt to build a long-term reputation for 
quality, but rather maximize the short-run profits from attracting clicks in an initial period. Capturing precisely how this competition plays out on social media would require extending the model to include multiple steps where consumers see "headlines" and then decide whether to "click" to learn more detail. But loosely speaking, we can imagine that such firms attract demand because consumers cannot distinguish them from higher-quality outlets, and also because their reports are tailored to deliver psychological utility to consumers on either the left or right of the political spectrum.

Adding fake news producers to a market has several potential social costs. First, consumers who mistake a fake outlet for a legitimate one have less-accurate beliefs and are worse off for that reason. Second, these less-accurate beliefs may reduce positive social externalities, undermining the ability of the democratic process to select high-quality candidates. Third, consumers may also become more skeptical of legitimate news producers, to the extent that they become hard to distinguish from fake news producers. Fourth, these effects may be reinforced in equilibrium by supply-side responses: a reduced demand for high-precision, low-bias reporting will reduce the incentives to invest in accurate reporting and truthfully report signals. These negative effects trade off against any welfare gain that arises from consumers who enjoy reading fake news reports that are consistent with their priors.

\section{Real Data on Fake News}

\section{Fake News Database}

We gathered a database of fake news articles that circulated in the three months before the 2016 election, using lists from three independent third parties. First, we scraped all stories from the Donald Trump and Hillary Clinton tags on Snopes (snopes.com), which calls itself "the definitive Internet reference source for urban legends, folklore, myths, rumors, and misinformation." Second, we scraped all stories from the 2016 presidential election tag from PolitiFact (politifact.com), another major fact-checking site. Third, we use a list of 21 fake news articles that had received significant engagement on Facebook, as compiled by the news outlet BuzzFeed (Silverman 2016)..$^{4}$ Combining these three lists, we have a database of 156 fake news articles. We then gathered the total number of times each article was shared on Facebook as of early December 2016, using an online content database called BuzzSumo (buzzsumo.com). We code each article's content as either proClinton (including anti-Trump) or pro-Trump (including anti-Clinton).

This list is a reasonable but probably not comprehensive sample of the major fake news stories that circulated before the election. One measure of comprehensiveness is to look at the overlap between the lists of stories from Snopes, PolitiFact, and BuzzFeed. Snopes is our largest list, including 138 of our total of 156 articles. As

\footnotetext{
${ }^{4}$ Of these 21 articles, 12 were fact-checked on Snopes. Nine were rated as "false," and the other three were rated "mixture," "unproven," and "mostly false."
} 
a benchmark, 12 of the 21 articles in the BuzzFeed list appear in Snopes, and 4 of the 13 articles in the PolitiFact appear in Snopes. The lack of perfect overlap shows that none of these lists is complete and suggests that there may be other fake news articles that are omitted from our database.

\section{Post-Election Survey}

During the week of November 28, 2016, we conducted an online survey of 1208 US adults aged 18 and over using the SurveyMonkey platform. The sample was drawn from SurveyMonkey's Audience Panel, an opt-in panel recruited from the more than 30 million people who complete SurveyMonkey surveys every month (as described in more detail at https://www.surveymonkey.com/mp/audience/).

The survey consisted of four sections. First, we acquired consent to participate and a commitment to provide thoughtful answers, which we hoped would improve data quality. Those who did not agree were disqualified from the survey. Second, we asked a series of demographic questions, including political affiliation before the 2016 campaign, vote in the 2016 presidential election, education, and race/ ethnicity. Third, we asked about 2016 election news consumption, including time spent on reading, watching, or listening to election news in general and on social media in particular, and the most important source of news and information about the 2016 election. Fourth, we showed each respondent 15 news headlines about the 2016 election. For each headline, we asked, "Do you recall seeing this reported or discussed prior to the election?" and "At the time of the election, would your best guess have been that this statement was true?" We also received age and income categories, gender, and census division from profiling questions that respondents had completed when they first started taking surveys on the Audience panel. The survey instrument can be accessed at https:/ /www.surveymonkey.com/r/RSYD75P.

Each respondent's 15 news headlines were randomly selected from a list of 30 news headlines, six from each of five categories. Within each category, our list contains an equal split of pro-Clinton and pro-Trump headlines, so 15 of the 30 articles favored Clinton, and the other 15 favored Trump. The first category contains six fake news stories mentioned in three mainstream media articles (one in the New York Times, one in the Wall Street Journal, and one in BuzzFeed) discussing fake news during the week of November 14, 2016. The second category contains the four most recent pre-election headlines from each of Snopes and PolitiFact deemed to be unambiguously false. We refer to these two categories individually as "Big Fake" and "Small Fake," respectively, or collectively as "Fake." The third category contains the most recent six major election stories from the Guardian's election timeline. We refer to these as "Big True" stories. The fourth category contains the two most recent pre-election headlines from each of Snopes and PolitiFact deemed to be unambiguously true. We refer to these as "Small True" stories. Our headlines in these four categories appeared on or before November 7 .

The fifth and final category contains invented "Placebo" fake news headlines, which parallel placebo conspiracy theories employed in surveys by Oliver and Wood (2014) and Chapman University (2016). As we explain below, we include these 
Placebo headlines to help control for false recall in survey responses. We invented three damaging fake headlines that could apply to either Clinton or Trump, then randomized whether a survey respondent saw the pro-Clinton or pro-Trump version. We experimented with several alternative placebo headlines during a pilot survey, and we chose these three because the data showed them to be approximately equally believable as the "Small Fake" stories. (We confirmed using Google searches that none of the Placebo stories had appeared in actual fake news articles.) Online Appendix Table 1, available with this article at this journal's website (http:/ / e-jep.org), lists the exact text of the headlines presented in the survey. The online Appendix also presents a model of survey responses that makes precise the conditions under which differencing with respect to the placebo articles leads to valid inference.

Yeager et al. (2011) and others have shown that opt-in internet panels such as ours typically do not provide nationally representative results, even after reweighting. Notwithstanding, reweighting on observable variables such as education and internet usage can help to address the sample selection biases inherent in an opt-in internet-based sampling frame. For all results reported below, we reweight the online sample to match the nationwide adult population on ten characteristics that we hypothesized might be correlated with survey responses, including income, education, gender, age, ethnicity, political party affiliation, and how often the respondent reported consuming news from the web and from social media. The online Appendix includes summary statistics for these variables; our unweighted sample is disproportionately well-educated, female, and Caucasian, and those who rely relatively heavily on the web and social media for news. The Appendix also includes additional information on data construction.

\section{Social Media as a Source of Political Information}

The theoretical framework we sketched above suggests several reasons why social media platforms may be especially conducive to fake news. First, on social media, the fixed costs of entering the market and producing content are vanishingly small. This increases the relative profitability of the small-scale, short-term strategies often adopted by fake news producers, and reduces the relative importance of building a long-term reputation for quality. Second, the format of social media-thin slices of information viewed on phones or news feed windows - can make it difficult to judge an article's veracity. Third, Bakshy, Messing, and Adamic (2015) show that Facebook friend networks are ideologically segregated-among friendships between people who report ideological affiliations in their profiles, the median share of friends with the opposite ideology is only 20 percent for liberals and 18 percent for conservatives-and people are considerably more likely to read and share news articles that are aligned with their ideological positions. This suggests that people who get news from Facebook (or other social media) are less likely to receive evidence about the true state of the world that would counter an ideologically aligned but false story. 
Figure 3

\section{Share of Visits to US News Websites by Source}

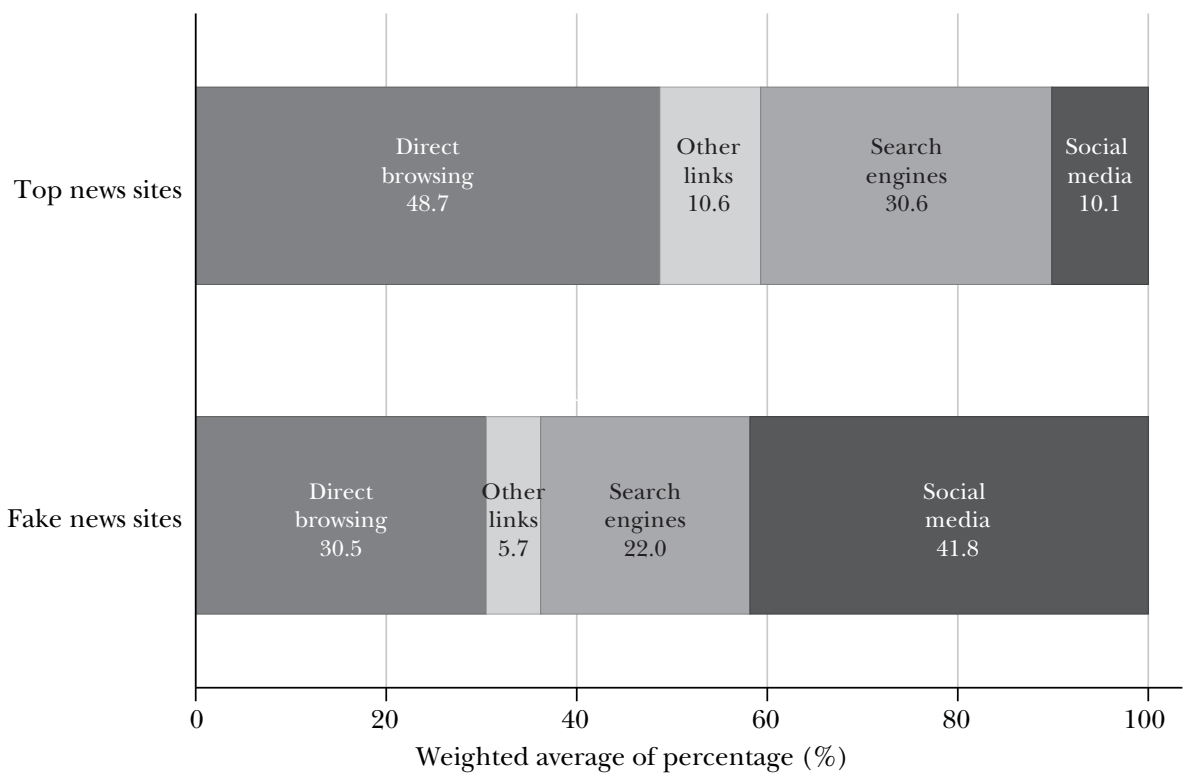

Note: This figure presents the share of traffic from different sources for the top 690 US news websites and for 65 fake news websites. "Other links" means impressions that were referred from sources other than search engines and social media. "Direct browsing" means impressions that did not have a referral source. Sites are weighted by number of monthly visits. Data are from Alexa.

One way to gauge the importance of social media for fake news suppliers is to measure the source of their web traffic. Each time a user visits a webpage, that user has either navigated directly (for example, by typing www.wsj.com into a browser) or has been referred from some other site. Major referral sources include social media (for example, clicking on a link in the Facebook news feed) and search engines (for example, searching for "Pope endorsed Trump?" on Google and clicking on a search result). Figure 3 presents web traffic sources for the month around the 2016 US presidential election (late October through late November) from Alexa (alexa.com), which gathers data from browser extensions installed on people's computers as well as from measurement services offered to websites. These data exclude mobile browsing and do not capture news viewed directly on social media sites, for example, when people read headlines within Facebook or Twitter news feeds.

The upper part of the graph presents referral sources for the top 690 US news sites, as ranked by Alexa. The lower part of the graph presents web traffic sources for a list of 65 major fake news sites, which we gathered from lists compiled by Zimdars (2016) and Brayton (2016). For the top news sites, social media referrals represent only about 10 percent of total traffic. By contrast, fake news websites rely on social 
media for a much higher share of their traffic. This demonstrates the importance of social media for fake news providers. While there is no definitive list of fake news sites, and one might disagree with the inclusion or exclusion of particular sites in this list of 65, this core point about the importance of social media for fake news providers is likely to be robust.

A recent Pew survey (Gottfried and Shearer 2016) finds that 62 percent of US adults get news from social media. To the extent that fake news is socially costly and fake news is prevalent on social media, this statistic could appear to be cause for concern. Of this 62 percent, however, only 18 percent report that they get news from social media "often," 26 percent do so "sometimes," and 18 percent do so "hardly ever." By comparison, the shares who "often" get news from local television, national broadcast television, and cable television are 46 percent, 30 percent, and 31 percent respectively. Moreover, only 34 percent of web-using adults trust the information they get from social media "some" or "a lot." By contrast, this share is 76 percent for national news organizations and 82 percent for local news organizations.

The results of our post-election survey are broadly consistent with this picture. For the month before the 2016 election, our respondents report spending 66 minutes per day reading, watching, or listening to election news. (Again, these and all other survey results are weighted for national representativeness.) Of this, 25 minutes (38 percent) was on social media. Our survey then asked, "Which of these sources was your most important source of news and information about the 2016 election?" The word "important" was designed to elicit a combination of consumption frequency and trust in information. Figure 4 presents responses. In order, the four most common responses are cable TV, network TV, websites, and local TV. Social media is the fifth most common response, with 14 percent of US adults listing social media as their most "important" news source.

Taken together, these results suggest that social media have become an important but not dominant source of political news and information. Television remains more important by a large margin.

\section{Partisanship of Fake News}

In our fake news database, we record 41 pro-Clinton (or anti-Trump) and 115 pro-Trump (or anti-Clinton) articles, which were shared on Facebook a total of 7.6 million and 30.3 million times, respectively. Thus, there are about three times more fake pro-Trump articles than pro-Clinton articles, and the average pro-Trump article was shared more on Facebook than the average pro-Clinton article. To be clear, these statistics show that more of the fake news articles on these three factchecking sites are right-leaning. This could be because more of the actual fake news is right-leaning, or because more right-leaning assertions are forwarded to and/or reported by fact-checking sites, or because the conclusions that fact-checking sites draw have a left-leaning bias, or some combination. Some anecdotal reports support the idea that the majority of election-related fake news was pro-Trump: some fake 
Figure 4

Most Important Source of 2016 Election News

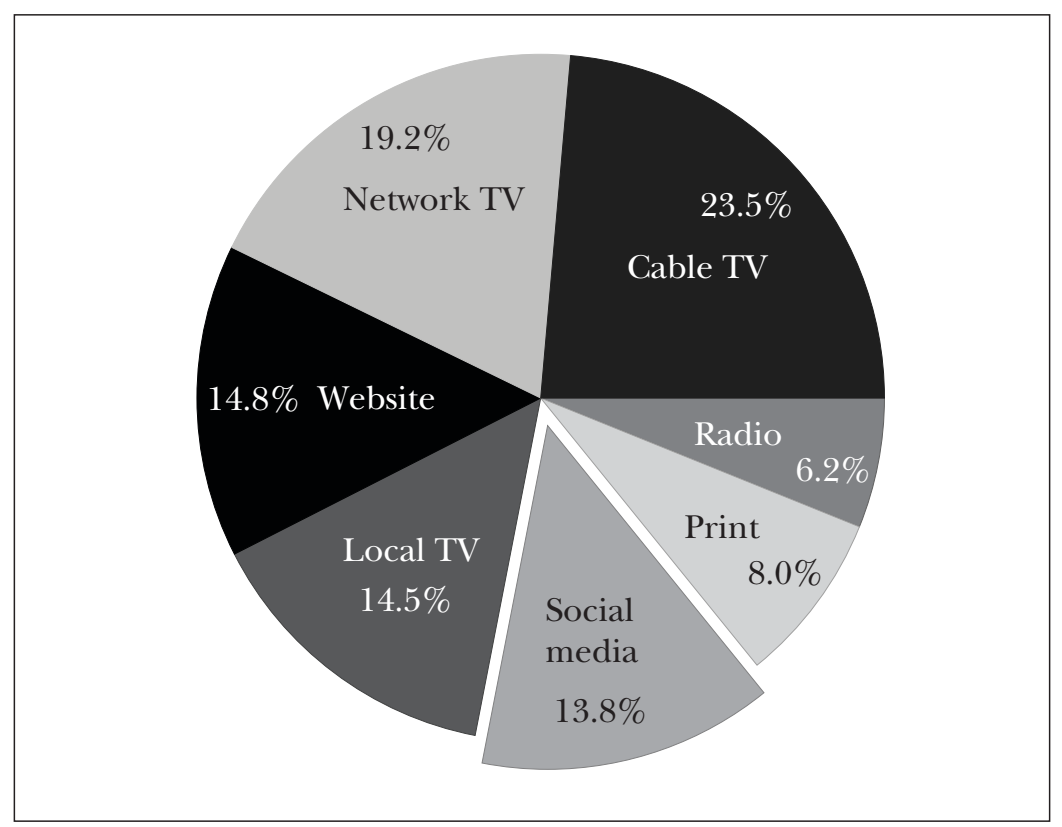

Notes: Our post-election survey asked, "Which of these sources was your most important source of news and information about the 2016 election?" This figure plots responses. Observations are weighted for national representativeness.

news providers reportedly found higher demand for pro-Trump (or anti-Clinton) fake news, and responded by providing more of it (Sydell 2016).

There could be several possible explanations for a preponderance of proTrump fake news. The more marked decline of trust in the mainstream media among Republicans shown in Figure 2 could have increased their relative demand for news from nontraditional sources, as could a perception that the mainstream media tended to favor Clinton. Pro-Trump (and anti-Clinton) storylines may have simply been more compelling than pro-Clinton (and anti-Trump) storylines due to particulars of these candidates, perhaps related to the high levels of media attention that Trump received throughout the campaign. Or, it could theoretically be that Republicans are for some reason more likely to enjoy or believe fake news.

Some prior evidence argues against the last hypothesis. McClosky and Chong (1985) and Uscinski, Klofstad, and Atkinson (2016) find that people on the left and right are equally disposed to conspiratorial thinking. Furthermore, Bakshy, Messing, and Adamic (2015) find that conservatives are actually exposed to more cross-cutting news content than liberals, which could help conservatives to be better at detecting partisan fake news. Below, we present further evidence on this hypothesis from our survey. 


\section{Exposure to Fake News}

How much fake news did the typical voter see in the run-up to the 2016 election? While there is a long literature measuring media exposure (for example, Price and Zaller 1993), fake news presents a particular challenge: much of its circulation is on Facebook (and other social media) news feeds, and these data are not public. We provide three benchmarks for election-period fake news exposure, which we report as average exposure for each of the 248 million American adults.

First, we can use prior evidence to predict the number of times the articles in our database were read based on the number of times they were shared. The corporate website of Eventbrite (2012) reports that links to its events on Facebook generate 14 page visits per share. A blog post by Jessica Novak (undated) reports that for a set of "top performing" stories on Facebook the ratio of visits to shares was also 14. Zhao, Wang, Tao, Ma, and Guan (2013) report that the ratio of views to shares for videos on the Chinese social networking site Renren ranges from 3 to 8 . Based on these very rough reference points, we consider a ratio of 20 page visits per share as an upper bound on the plausible range. This implies that the 38 million shares of fake news in our database translate into 760 million page visits, or about three visits per US adult.

Second, we can use web browsing data to measure impressions on fake news websites. For the month around the 2016 election, there were 159 million impressions on the 65 websites in the bottom part of Figure 3, or 0.64 impressions per adult. This is dwarfed by the 3 billion impressions on the 665 top news websites over the same period. Furthermore, not all content on these 65 sites is false: in a random sample of articles from these sites, we categorized just under 55 percent as false, either because the claim was refuted by a mainstream news site or fact-checking organization, or because the claim was not covered on any other sites despite being important enough that it would have been covered on other sites if it were true. When comparing these first two approaches to estimating election-period fake news exposure, remember that the first approach uses cumulative Facebook shares as of early December 2016 for fake news articles that were fact-checked in the three months before the election, while the second approach uses web traffic from a one month period between late October to late November 2016.

Third, we can use our post-election survey to estimate the number of articles respondents saw and remembered. The survey gave respondents 15 news headlines-three headlines randomly selected from each of the five categories detailed earlier-and asked if they recalled seeing the headline ("Do you recall seeing this reported or discussed prior to the election?") and if they believed it ("At the time of the election, would your best guess have been that this statement was true?").

Figure 5 presents the share of respondents that recalled seeing (left bar) and seeing and believing (right bar) headlines, averaging responses across all the headlines within each of our main categories. Rates of both seeing and believing are much higher for true than fake stories, and they are substantially higher for the "Big True" headlines (the major headlines leading up to the election) than for the 
Figure 5

\section{Percent of US Adult Population that Recall Seeing or that Believed Election} News

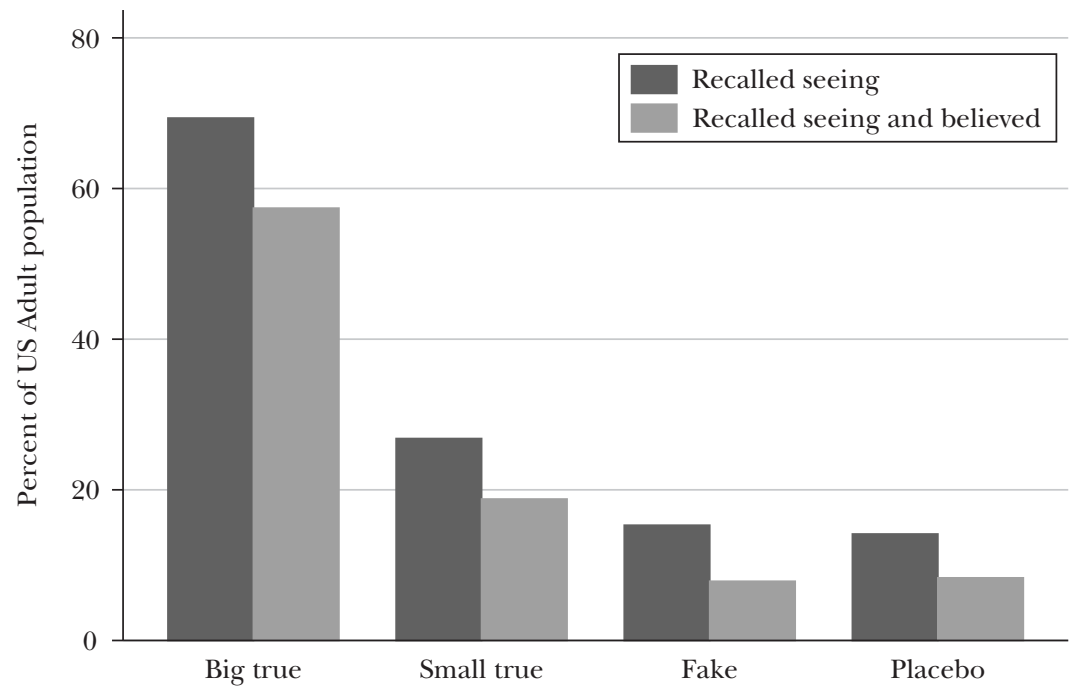

Notes: In our post-election survey, we presented 15 headlines. For each headline, the survey asked whether respondents recall seeing the headline ("Do you recall seeing this reported or discussed before the election?") and whether they believed it ("At the time of the election, would your best guess have been that this statement was true?"). The left bars present the share of respondents who recall seeing the headlines in each category, and the right bars present the share of respondents who recall seeing and believed the headlines. "Big True" headlines are major headlines leading up to the election; "Small True" headlines are the minor fact-checked headlines that we gathered from Snopes and PolitiFact. The Placebo fake news headlines were made-up for the research and never actually circulated. Observations are weighted for national representativeness.

"Small True" headlines (the minor fact-checked headlines that we gathered from Snopes and PolitiFact). The Placebo fake news articles, which never actually circulated, are approximately equally likely to be recalled and believed as the Fake news articles which did actually circulate. This implies that there is a meaningful rate of false recall of articles that people never actually saw, which could cause the survey measure to significantly overstate true exposure. On the other hand, people likely forgot some of the Fake articles that they were actually exposed to, which causes the survey responses to understate true exposure.

In summary, one can think of recalled exposure as determined both by actual exposure and by the headline's perceived plausibility-people might think that if a headline is plausible, they probably saw it reported somewhere. Then, we show that if the Placebo headlines are equally plausible as the Fake headlines, the difference between recall of Fake and Placebo headlines represents the rate of true exposure that was remembered. The Appendix available online with this paper at http://e-jep.org presents additional theoretical and empirical discussion of false recall in our data. 
After weighting for national representativeness, 15 percent of survey respondents recalled seeing the Fake stories, and 8 percent both recalled seeing the story and said they believed it. 5 By comparison, about 14 percent of people report seeing the placebo stories, and about 8 percent report seeing and believing them. We estimate that the average Fake headline was 1.2 percentage points more likely to be seen and recalled than the average Placebo headline, and the 95 percent confidence interval allows us to exclude differences greater than 2.9 percent.

We can use these results to provide a separate estimate of fake news exposure. The average Fake article that we asked about in the post-election survey was shared 0.386 million times on Facebook. If the average article was seen and recalled by 1.2 percent of American adults, this gives (0.012 recalled exposure)/ (0.386 million shares $) \approx 0.03$ chance of a recalled exposure per million Facebook shares. Given that the Fake articles in our database had 38 million Facebook shares, this implies that the average adult saw and remembered $0.03 /$ million $\times 38$ million $\approx 1.14$ fake news articles from our fake news database.

All three approaches suggest that election-period fake news exposure was on the order of one or perhaps several articles read per adult. We emphasize several important caveats. First, each of these measures excludes some forms of exposure that could have been influential. All of them exclude stories or sites omitted from our database. Estimated page visits or impressions exclude cases in which users saw a story within their Facebook news feed but did not click through to read it. Our survey-based recall measure excludes stories that users saw but did not remember, and may be subject to other biases associated with survey-based estimates of media exposure (Bartels 1993; Prior 2009; Guess 2015).

\section{Who Believes Fake News?}

It is both privately and socially valuable when people can infer the true state of the world. What factors predict the ability to distinguish between real and fake news? This analysis parallels a literature in political science measuring and interpreting correlates of misinformation, including Lewandowsky, Oberauer, and Gignac (2013), Malka, Krosnick, and Langer (2009), and Oliver and Wood (2014).

We construct a variable $C_{i a}$, that takes value 1 if survey respondent $i$ correctly identifies whether article $a$ is true or false, 0.5 if respondent $i$ is "not sure," and value 0 otherwise. For example, if headline $a$ is true, then $C_{i a}$ takes value 1 if person $i$ responded "Yes" to "would your best guess have been that this statement was true?"; 0.5 if person $i$ responded "Not sure"; and 0 if person $i$ responded "No." We use $C_{i a}$

\footnotetext{
${ }^{5}$ These shares are broadly consistent with the results of a separate survey conducted by Silverman and Singer-Vine (2016): for a set of five fake news stories, they find that the share of respondents who have heard them ranges from 10 to 22 percent and the share who rate them as "very accurate" ranges from 28 to 49 percent.
} 
as the dependent variable and a vector $\mathbf{X}_{i}$ of individual characteristics in a linear regression:

$$
C_{i a}=\boldsymbol{\alpha}_{1} \mathbf{X}_{i}+\alpha_{0}+\varepsilon_{i a}
$$

Table 1 reports results. Column 1 includes only false articles (both Fake and Placebo), and focuses only on party affiliation; the omitted category is Independents. In these data, it is indeed true that Republicans were statistically less likely than Democrats to report that they (correctly) did not believe a false article. Column 2 includes only true articles (both Big True and Small True categories). This suggests that Republicans are also more likely than Democrats to correctly believe articles that were true $(p=0.124)$. These results suggest that in our data, Republicans were not generally worse at inference: instead, they tended to be more credulous of both true and false articles. Of course, it is possible that this is simply an artifact of how different respondents interpreted the survey design. For example, it could be that Republicans tended to expect a higher share of true headlines in our survey, and thus were less discerning.

Another possible explanation is that the differences between parties hide other factors associated with party affiliation. Columns 3 and 4 test this possibility, including a vector of additional covariates. The differences between the Democrat and Republican indicator variables are relatively robust. Column 5 includes all articles, which weights true and false articles by the proportions in our survey sample. Given that our survey included a large proportion of fake articles that Republicans were less likely to recognize as false, Democrats are overall more likely to correctly identify true versus false articles. Three correlations tend to be statistically significant: people who spend more time consuming media, people with higher education, and older people have more accurate beliefs about news. As with Republicans relative to Democrats, people who report that social media were their most important sources of election news were more likely both to correctly believe true headlines and to incorrectly believe false headlines.

The association of education with correct beliefs should be highlighted. Flynn, Nyhan, and Reifler (2017) argue that education could have opposing effects on political misperceptions. On the one hand, education should increase people's ability to discern fact from fiction. On the other hand, in the presence of motivated reasoning, education gives people better tools to counterargue against incongruent information. To the extent that the association in our data is causal, it would reinforce many previous arguments that the social return to education includes cognitive abilities that better equip citizens to make informed voting decisions. For example, Adam Smith (1776) wrote, "The more [people] are instructed, the less liable they are to the delusions of enthusiasm and superstition, which, among ignorant nations, frequently occasion the most dreadful disorders."

A common finding in the survey literature on rumors, conspiracy theories, and factual beliefs is that partisan attachment is an important predictor of beliefs (for example, Oliver and Wood 2014; Uscinski, Klofstad, and Atkinson 2016). 
Table 1

What Predicts Correct Beliefs about News Headlines?

\begin{tabular}{|c|c|c|c|c|c|}
\hline & (1) & (2) & (3) & (4) & (5) \\
\hline Democrat & $\begin{array}{c}0.029 \\
(0.020)\end{array}$ & $\begin{array}{l}-0.004 \\
(0.023)\end{array}$ & $\begin{array}{c}0.028 \\
(0.019)\end{array}$ & $\begin{array}{l}-0.010 \\
(0.021)\end{array}$ & $\begin{array}{c}0.015 \\
(0.013)\end{array}$ \\
\hline Republican & $\begin{array}{l}-0.024 \\
(0.024)\end{array}$ & $\begin{array}{c}0.040 \\
(0.027)\end{array}$ & $\begin{array}{l}-0.037 * \\
(0.020)\end{array}$ & $\begin{array}{c}0.021 \\
(0.023)\end{array}$ & $\begin{array}{l}-0.018 \\
(0.014)\end{array}$ \\
\hline $\ln$ (Daily media time) & & & $\begin{array}{l}-0.002 \\
(0.007)\end{array}$ & $\begin{array}{l}0.042^{* * * *} \\
(0.008)\end{array}$ & $\begin{array}{l}0.013 * * * \\
(0.004)\end{array}$ \\
\hline $\begin{array}{l}\text { Social media most } \\
\text { important }\end{array}$ & & & $\begin{array}{l}-0.066^{* * * *} \\
(0.025)\end{array}$ & $\begin{array}{l}0.065^{* * * *} \\
(0.024)\end{array}$ & $\begin{array}{l}-0.023 \\
(0.016)\end{array}$ \\
\hline Use social media & & & $\begin{array}{c}0.014 \\
(0.030)\end{array}$ & $\begin{array}{l}-0.023 \\
(0.038)\end{array}$ & $\begin{array}{c}0.002 \\
(0.019)\end{array}$ \\
\hline $\begin{array}{l}\text { Social media } \\
\text { ideological segregation }\end{array}$ & & & $\begin{array}{l}-0.027 \\
(0.036)\end{array}$ & $\begin{array}{c}0.028 \\
(0.046)\end{array}$ & $\begin{array}{l}-0.008 \\
(0.024)\end{array}$ \\
\hline Education & & & $\begin{array}{l}0.014^{* * * *} \\
(0.004)\end{array}$ & $\begin{array}{c}0.004 \\
(0.004)\end{array}$ & $\begin{array}{l}0.011 * * * \\
(0.003)\end{array}$ \\
\hline Undecided & & & $\begin{array}{l}-0.011 \\
(0.017)\end{array}$ & $\begin{array}{c}0.006 \\
(0.022)\end{array}$ & $\begin{array}{l}-0.005 \\
(0.013)\end{array}$ \\
\hline Age & & & $\begin{array}{l}0.002^{* * * *} \\
(0.000)\end{array}$ & $\begin{array}{c}0.000 \\
(0.001)\end{array}$ & $\begin{array}{l}0.002 * * * \\
(0.000)\end{array}$ \\
\hline$N$ & 12,080 & 6,040 & 12,080 & 6,040 & 18,120 \\
\hline $\begin{array}{l}p \text {-value } \\
\quad(\text { Democrat }=\text { Republican })\end{array}$ & 0.029 & 0.124 & 0.004 & 0.207 & 0.035 \\
\hline Articles in sample & False & True & False & True & All \\
\hline
\end{tabular}

Note: This table presents estimates of a regression of a dependent variable measuring correct beliefs about headlines on individual characteristics. Columns 1 and 3 include only false headlines, columns 2 and 4 contain only true headlines, and column 5 contains all headlines. All columns include additional demographic controls: income, race, and gender. "Social media most important" means social media were the respondent's most important sources of election news. "Social media ideological segregation" is the self-reported share (from 0 to 1 ) of social media friends that preferred the same presidential candidate. "Undecided" is an indicator variable for whether the respondent decided which candidate to vote for less than three months before the election. Observations are weighted for national representativeness. Standard errors are robust and clustered by survey respondent.

$*$, **, *** indicate statistically significantly different from zero with 90,95 , and 99 percent confidence, respectively.

For example, Republicans are more likely than Democrats to believe that President Obama was born outside the United States, and Democrats are more likely than Republicans to believe that President Bush was complicit in the 9/11 attacks (Cassino and Jenkins 2013). Such polarized beliefs are consistent with a Bayesian framework, where posteriors depend partially on priors, as well as with models of motivated reasoning (for example, Taber and Lodge 2006, or see the symposium in the Summer 2016 issue of this journal). Either way, the ability to update one's priors in response to factual information is privately and socially valuable in our model, and polarized views on factual issues can damage society's ability to come 
to agreement on what social problems are important and how to address them (Sunstein 2001a, b, 2007).

Given this discussion, do we also see polarized beliefs with respect to fake news? And if so, what factors moderate ideologically aligned inference-that is, what factors predict a lower probability that a Republican is more likely to believe proTrump news than pro-Clinton news, or that a Democrat is more likely to believe pro-Clinton than pro-Trump news? To gain insight into this question, we define $B_{i a}$ as a measure of whether individual $i$ believed article $a$, taking value 1 if "Yes," 0.5 if "Not sure," and 0 if "No." We also define $D_{i}$ and $R_{i}$ as Democrat and Republican indicators, and $C_{a}$ and $T_{a}$ as indicators for whether headline $a$ is pro-Clinton or pro-Trump. We then run the following regression in the sample of Democrats and Republicans, excluding Independents:

$$
B_{i a}=\beta_{D} D_{i} C_{a}+\beta_{R} R_{i} T_{a}+\gamma_{D} D_{i}+\gamma_{R} R_{i}+\varepsilon_{i a} .
$$

The first two independent variables are interaction terms; their coefficients $\beta_{D}$ and $\beta_{R}$ measure whether a Democrat is more likely to believe a pro-Clinton headline and whether a Republican is more likely to believe a pro-Trump headline. The second two independent variables control for how likely Democrats or Republicans are as a group are to believe all stories. Since headlines are randomly assigned to respondents, with equal balance of true versus false and pro-Trump versus proClinton, the estimated $\beta$ parameters will measure ideologically aligned inference

Table 2 presents the results. Column 1 presents estimates of $\beta_{D}$ and $\beta_{R}$. Democrats and Republicans, respectively, are 17.2 and 14.7 percentage points more likely to believe ideologically aligned articles than they are to believe nonaligned articles. Column 2 takes an intermediate step, constraining the $\beta$ coefficients to be the same. Column 3 then allows $\beta$ to vary by the same vector of $\mathbf{X}_{i}$ variables as reported in Table 1, except excluding $D_{i}$ to avoid collinearity. In both columns 1 and 3 , any differences between Democrats and Republicans in the magnitude of ideologically aligned inference are not statistically significant.

Three variables are strongly correlated with ideologically aligned inference. First, heavy media consumers are more likely to believe ideologically aligned articles. Second, those with segregated social networks are significantly more likely to believe ideologically aligned articles, perhaps because they are less likely to receive disconfirmatory information from their friends. The point estimate implies that a 0.1 (10 percentage point) increase in the share of social media friends that preferred the same presidential candidate is associated with a 0.0147 (1.47 percentage point) increase in belief of ideologically aligned headlines relative to ideologically crosscutting headlines. Third, "undecided" adults (those who did not make up their minds about whom to vote for until less than three months before the election) are less likely to believe ideologically aligned articles than more decisive voters. This is consistent with undecided voters having less-strong ideologies in the first place. Interestingly, social media use and education are not statistically significantly associated with more or less ideologically aligned inference. 
Table 2

\section{Ideological Alignment and Belief of News Headlines}

\begin{tabular}{|c|c|c|c|}
\hline & (1) & $(2)$ & (3) \\
\hline Democrat $\times$ Pro-Clinton & $\begin{array}{l}0.172 * * * \\
(0.021)\end{array}$ & & \\
\hline Republican $\times$ Pro-Trump & $\begin{array}{l}0.147 * * * \\
(0.023)\end{array}$ & & \\
\hline Aligned & & $\begin{array}{l}0.161 * * * \\
(0.016)\end{array}$ & $\begin{array}{c}0.096 \\
(0.140)\end{array}$ \\
\hline Aligned $\times$ Republican & & & $\begin{array}{c}0.000 \\
(0.027)\end{array}$ \\
\hline Aligned $\times \ln ($ Daily media time $)$ & & & $\begin{array}{l}0.024 * * * \\
(0.009)\end{array}$ \\
\hline Aligned $\times$ Social media most important & & & $\begin{array}{c}-0.031 \\
(0.037)\end{array}$ \\
\hline Aligned $\times$ Use social media & & & $\begin{array}{c}-0.068 \\
(0.050)\end{array}$ \\
\hline Aligned $\times$ Social media ideological segregation & & & $\begin{array}{l}0.147^{* * * *} \\
(0.046)\end{array}$ \\
\hline Aligned $\times$ Education & & & $\begin{array}{c}-0.004 \\
(0.007)\end{array}$ \\
\hline Aligned $\times$ Undecided & & & $\begin{array}{c}-0.099 * * * \\
(0.030)\end{array}$ \\
\hline Aligned $\times$ Age & & & $\begin{array}{c}0.001 \\
(0.001)\end{array}$ \\
\hline$N$ & 10,785 & 10,785 & 10,785 \\
\hline
\end{tabular}

Notes: This table presents estimates of a regression of a variable measuring belief of news headlines on the interaction of political party affiliation indicators and pro-Clinton or pro-Trump headline indicators. The sample includes all news headlines (both true and false) but excludes survey respondents who are Independents. "Social media most important" means social media were the respondent's most important sources of election news. "Social media ideological segregation" is the self-reported share (from 0 to 1 ) of social media friends that preferred the same presidential candidate. "Undecided" is an indicator variable for whether the respondent decided which candidate to vote for less than three months before the election. Observations are weighted for national representativeness. Standard errors are robust and clustered by survey respondent. $*$ **, ***: statistically significantly different from zero with 90, 95, and 99 percent confidence, respectively.

One caveat to these results is that ideologically aligned inference may be exaggerated by respondents' tendency to answer expressively or to want to "cheerlead" for their party (Bullock, Gerber, Hill, and Huber 2015; Gerber and Huber 2009; Prior, Sood, and Khanna 2015). Partisan gaps could be smaller in a survey with strong incentives for correct answers. 


\section{Conclusion}

In the aftermath of the 2016 US presidential election, it was alleged that fake news might have been pivotal in the election of President Trump. We do not provide an assessment of this claim one way or another.

That said, the new evidence we present clarifies the level of overall exposure to fake news, and it can give some sense of how persuasive fake news would need to have been to have been pivotal. We estimate that the average US adult read and remembered on the order of one or perhaps several fake news articles during the election period, with higher exposure to pro-Trump articles than pro-Clinton articles. How much this affected the election results depends on the effectiveness of fake news exposure in changing the way people vote. As one benchmark, Spenkuch and Toniatti (2016) show that exposing voters to one additional television campaign ad changes vote shares by approximately 0.02 percentage points. This suggests that if one fake news article were about as persuasive as one TV campaign ad, the fake news in our database would have changed vote shares by an amount on the order of hundredths of a percentage point. This is much smaller than Trump's margin of victory in the pivotal states on which the outcome depended.

Of course there are many reasons why a single fake news story could have been more effective than a television commercial. If it were true that the Pope endorsed Donald Trump, this fact would be significantly more surprising-and probably move a rational voter's beliefs by more as a result - than the information contained in a typical campaign ad. Moreover, as we emphasize above, there are many ways in which our estimates could understate true exposure. We only measure the number of stories read and remembered, and the excluded stories seen on news feeds but not read, or read but not remembered, could have had a large impact. Our fake news database is incomplete, and the effect of the stories it omits could also be significant.

We also note that there are several ways in which this back-of-the-envelope calculation is conservative, in the sense that it could overstate the importance of fake news. We consider the number of stories voters read regardless of whether they believed them. We do not account for diminishing returns, which could reduce fake news' effect to the extent that a small number of voters see a large number of stories. Also, this rough calculation does not explicitly take into account the fact that a large share of pro-Trump fake news is seen by voters who are already predisposed to vote for Trump-the larger this selective exposure, the smaller the impact we would expect of fake news on vote shares.

To the extent that fake news imposes social costs, what can and should be done? In theory, a social planner should want to address the market failures that lead to distortions, which would take the form of increasing information about the state of the world and increasing incentives for news consumers to infer the true state of the world. In practice, social media platforms and advertising networks have faced some pressure from consumers and civil society to reduce the prevalence of fake news on their systems. For example, both Facebook and Google are removing fake news sites 
from their advertising platforms on the grounds that they violate policies against misleading content (Wingfield, Isaac, and Benner 2016). Furthermore, Facebook has taken steps to identify fake news articles, flag false articles as "disputed by 3rd party fact-checkers," show fewer potentially false articles in users' news feeds, and help users avoid accidentally sharing false articles by notifying them that a story is "disputed by 3rd parties" before they share it (Mosseri 2016). In our theoretical framework, these actions may increase social welfare, but identifying fake news sites and articles also raises important questions about who becomes the arbiter of truth.

- We thank David Deming, Brendan Nyhan, Craig Silverman, Aaron Smith, Joe Uscinski, David Vannette, and many other colleagues for helpful conversations and feedback. We are grateful to Chuan Yu and Nano Barahona for research assistance, and we thank Stanford University for financial support. Our survey was determined to be exempt from human subjects review by the NYU and Stanford Institutional Review Boards.

\section{References}

Abramowitz, Alan I., and Kyle L. Saunders. 2008. "Is Polarization a Myth?" Journal of Politics $70(2): 542-55$.

American Enterprise Institute. 2013. "Public Opinion on Conspiracy Theories." AEI Public Opinion Study. Compiled by Karlyn Bowman and Andrew Rugg. November, https://www.aei.org/ wp-content/uploads/2013/11/-public-opinionon-conspiracy-theories_181649218739.pdf.

American National Election Studies. 2010. Times Series Cumulative Data File [dataset]. Produced and distributed by Stanford University and the University of Michigan. http://www. electionstudies.org/studypages/anes_timeseries_ cdf/anes_timeseries_cdf.htm.

Bagdikian, Ben H. 1983. The Media Monopoly. Beacon Press.

Bakshy, Eytan, Solomon Messing, and Lada A. Adamic. 2015. "Exposure to Ideologically Diverse News and Opinion on Facebook." Science 348(6239): 1130-32.

-Bartels, Larry M. 1993. "Messages Received: The Political Impact of Media Exposure." American Political Science Review 87(2): 267-85.

Berinsky, Adam J. 2017. "Rumors and Health Care Reform: Experiments in Political Misinformation." British Journal of Political Science 47(2): 241-62.

Brayton, Ed. 2016. "Please Stop Sharing Links to These Sites." Patheos, September 18. http://www. patheos.com/blogs/dispatches/2016/09/18/ please-stop-sharing-links-to-these-sites/.

Bullock, John G., Alan S. Gerber, Seth J. Hill, and Gregory A. Huber. 2015. "Partisan Bias in Factual Beliefs about Politics." Quarterly Journal of Political Science 10(4): 519-78.

BuzzFeed News. No date. "Election Content Engagement." [A spreadsheet] https://docs. google.com/spreadsheets/d/1ysnzawW6pDG BEqbXqeYuzWa7Rx2mQUip6CXUUUk4jIk/ edit\#gid=1756764129.

Cassino, Dan, and Krista Jenkins. 2013. "Conspiracy Theories Prosper: 25\% of Americans Are 'Truthers."' Fairleigh Dickinson University's Public Mind Poll. January 17. http://publicmind. fdu.edu/2013/outthere.

Chapman University. 2016. "What Aren't They Telling Us?" Chapman University Survey of American Fears. October 11. https://blogs.chapman. edu/wilkinson/2016/10/11/what-arent-theytelling-us/.

DellaVigna, Stefano, and Matthew Gentzkow. 2010. "Persuasion: Empirical Evidence." Annual Review of Economics 2: 643-69.

DellaVigna, Stefano, and Ethan Kaplan. 2007. "The Fox News Effect: Media Bias and Voting." Quarterly Journal of Economics 122(3): 1187-1234.

Dewey, Caitlin. 2014. "This Is Not an Interview with Banksy." Washington Post, October 22. https:// www.washingtonpost.com/news/the-intersect/ $\mathrm{wp} / 2014 / 10 / 21 /$ this-is-not-an-interview-withbanksy/?tid=a_inl\&utm_term=.8a9 5d83438e9. 
Dewey, Caitlin. 2016. "Facebook Fake-News Writer: 'I Think Donald Trump is in the White House because of Me." Washington Post, November, 17. https://www.washingtonpost. com/news/the-intersect/wp/2016/11/17/ facebook-fake-news-writer-i-think-donald-trump-isin-the-white-house-because-of-me/.

DiFonzo, Nicholas, and Prashant Bordia. 2007. Rumor Psychology: Social and Organizational Approaches. American Psychological Association.

Enikolopov, Ruben, Maria Petrova, and Ekaterina Zhuravskaya. 2011. "Media and Political Persuasion: Evidence from Russia.” American Economic Review 101 (7): 3253-85.

Eventbrite. 2012. "Social Commerce: A Global Look at the Numbers." October 23. https://www. eventbrite.com/blog/ds00-social-commerce-aglobal-look-at-the-numbers /.

Fiorina, Morris P., and Samuel J. Abrams. 2008. "Political Polarization in the American Public." Annual Review of Political Science 11: 563-88.

Flaxman, Seth, Sharad Goel, and Justin M. Rao. 2016. "Filter Bubbles, Echo Chambers, and Online News Consumption.” Public Opinion Quarterly 80(1): 298-320.

Flynn, D. J., Brendan Nyhan, and Jason Reifler. 2017. "The Nature and Origins of Misperceptions: Understanding False and Unsupported Beliefs about Politics." Advances in Political Psychology 38(S1): 127-50.

Friggeri, Adrien, Lada Adamic, Dean Eckles, and Justin Cheng. 2014. "Rumor Cascades." Eighth International AAAI Conference on Weblogs and Social Media.

Gentzkow, Matthew, and Jesse M. Shapiro. 2006. "Media Bias and Reputation." Journal of Political Economy 114(2): 280-316.

Gentzkow, Matthew, and Jesse M. Shapiro. 2011. "Ideological Segregation Online and Offline." Quarterly Journal of Economics 126(4): 1799-1839.

Gentzkow, Matthew, Jesse M. Shapiro, and Daniel F. Stone. 2016. "Media Bias in the Marketplace: Theory." Chap. 14 in Handbook of Media Economics, vol. 1B, edited by Simon Anderson, Joel Waldofgel, and David Stromberg.

Gerber, Alan S., James G. Gimpel, Donald P. Green, and Daron R. Shaw. 2011. "How Large and Long-lasting are the Persuasive Effects of Televised Campaign Ads? Results from a Randomized Field Experiment." American Political Science Review 105(1): 135-150.

Gerber, Alan S., and Donald P. Green. 2000. "The Effects of Canvassing, Telephone Calls, and Direct Mail on Voter Turnout: A Field Experiment." American Political Science Review 94(3): 653-63.

Gerber, Alan S., and Gregory A. Huber. 2009. "Partisanship and Economic Behavior: Do Partisan
Differences in Economic Forecasts Predict Real Economic Behavior?" American Political Science Review 103(3): 407-26.

Gottfried, Jeffrey, and Elisa Shearer. 2016. "News Use across Social Media Platforms 2016." Pew Research Center, May 26. http://www. journalism.org/2016/05/26/news-use-acrosssocial-media-platforms-2016.

Guess, Andrew M. 2015. "Measure for Measure: An Experimental Test of Online Political Media Exposure." Political Analysis 23(1): 59-75.

-Huber, Gregory A., and Kevin Arceneaux. 2007. "Identifying the Persuasive Effects of Presidential Advertising." American Journal of Political Science 51(4): 957-77.

Kaplan, Richard L. 2002. Politics and the American Press: The Rise of Objectivity, 1865-1920. Cambridge University Press.

Keeley, Brian L. 1999. "Of Conspiracy Theories." Journal of Philosophy 96(3): 109-26.

Lang, Kurt, and Gladys Engel Lang. 2002. Television and Politics. Transaction Publishers.

Lelkes, Yphtach. 2016. "Mass Polarization: Manifestations and Measurements." Public Opinion Quarterly 80(S1): 392-410.

Lewandowsky, Stephan, Gilles E. Gignac, and Klaus Oberauer. 2013. "The Role of Conspiracist Ideation and Worldviews in Predicting Rejection of Science.” PloS One 8(10): e75637.

Malka, Ariel, Jon A. Krosnick, and Gary Langer. 2009. "The Association of Knowledge with Concern about Global Warming: Trusted Information Sources Shape Public Thinking." Risk Analysis 29(5): 633-47.

Martin, Gregory J., and Ali Yurukoglu. 2014. "Bias in Cable News: Persuasion and Polarization." NBER Working Paper 20798.

McClosky, Herbert, and Dennis Chong. 1985. "Similarities and Differences between Left-Wing and Right-Wing Radicals." British Journal of Political Science 15(3): 329-63.

Mosseri Adam. 2016. "News Feed FYI: Addressing Hoaxes and Fake News." Newsroom, Facebook, December 15. http://newsroom.fb. com/news/2016/12/news-feed-fyi-addressinghoaxes-and-fake-news/.

Mullainathan, Sendhil, and Andrei Shleifer. 2005. "The Market for News." American Economic Review 95(4): 1031-53.

Napoli, Philip M. 2014. "Measuring Media Impact: An Overview of the Field." Norman Lear Center Media Impact Project. https://learcenter. org/pdf/measuringmedia.pdf.

Novak, Jessica. No date. "Quantifying Virality: The Visits to Share Ratio.” http://intelligence.r29. com/post/105605860880/quantifying-virality-thevisits-to-shares-ratio. 
Dyhan, Brendan, Jason Reifler, Sean Richey, and Gary L. Freed. 2014. "Effective Messages in Vaccine Promotion: A Randomized Trial." Pediatrics 133(4): 835-42.

- Nyhan, Brendan, Jason Reifler, and Peter A. Ubel. 2013. "The Hazards of Correcting Myths about Health Care Reform.” Medical Care 51(2): 127-32.

-Oliver, J. Eric, and Thomas J. Wood. 2014. "Conspiracy Theories and the Paranoid Style(s) of Mass Opinion." American Journal of Political Science 58(4): 952-66.

Pariser, Eli. 2011. The Filter Bubble: What the Internet Is Hiding from You. Penguin UK.

Parkinson, Hannah Jane. 2016. "Click and Elect: How Fake News Helped Donald Trump Win a Real Election." Guardian, November 14.

PolitiFact. No date. http://www.politifact.com/ truth-o-meter/elections/2016/president-unitedstates/.

Price, Vincent, and John Zaller. 1993. "Who Gets the News? Alternative Measures of News Reception and Their Implications for Research." Public Opinion Quarterly 57(2): 133-64.

Prior, Markus. 2009. "The Immensely Inflated News Audience: Assessing Bias in Self-Reported News Exposure." Public Opinion Quarterly 73(1): 130-43.

Prior, Markus. 2013. "Media and Political Polarization." Annual Review of Political Science 16: 101-27.

Prior, Markus, Gaurav Sood, and Kabir Khanna. 2015. "You Cannot Be Serious: The Impact of Accuracy Incentives on Partisan Bias in Reports of Economic Perceptions." Quarterly Journal of Political Science 10(4): 489-518.

Read, Max. 2016. "Donald Trump Won because of Facebook." New York Magazine, November 9.

Silverman, Craig. 2016. "This Analysis Shows how Fake Election News Stories Outperformed Real News on Facebook." BuzzFeed News, November 16.

Silverman, Craig and Jeremy Singer-Vine. 2016. "Most Americans Who See Fake News Believe It, New Survey Says." BuzzFeed News, December 6.

Smith, Adam. 1776. The Wealth of Nations. London: W. Strahan.

Spenkuch, Jörg L., and David Toniatti. 2016. "Political Advertising and Election Outcomes." CESifo Working Paper Series 5780.

Subramanian, Samanth. 2017. "Inside the Macedonian Fake-News Complex, Wired, February 15.
Sunstein, Cass R. 2001a. Echo Chambers: Bush v. Gore, Impeachment, and Beyond. Princeton University Press.

Sunstein, Cass R. 2001b. Republic.com. Princeton University Press.

Sunstein, Cass R. 2007. Republic.com 2.0. Princeton University Press.

Swift, Art. 2016. "Americans' Trust in Mass Media Sinks to New Low.” Gallup, September 14. http://www.gallup.com/poll/195542/americanstrust-mass-media-sinks-new-low.aspx.

Sydell, Laura. 2016. "We Tracked Down a Fake-News Creator in the Suburbs. Here's What We Learned." National Public Radio, November 23. http://www.npr.org/sections/ alltechconsidered/2016/11/23/503146770/ npr-finds-the-head-of-a-covert-fake-news-operationin-the-suburbs.

Taber, Charles S., and Milton Lodge. 2006. "Motivated Skepticism in the Evaluation of Political Beliefs." American Journal of Political Science 50(3): 755-69.

Townsend, Tess. 2016. "Meet the Romanian Trump Fan behind a Major Fake News Site." Inc. http://www. inc.com/tess-townsend/ending-fedtrump-facebook.html.

Uscinski, Joseph E., Casey Klofstad, and Matthew D. Atkinson. 2016. "What Drives Conspiratorial Beliefs? The Role of Informational Cues and Predispositions." Political Research Quarterly 69(1): 57-71.

Wingfield, Nick, Mike Isaac, and Katie Benner. 2016." Google and Facebook Take Aim at Fake News Sites.” New York Times, November 14.

-Yeager, David S., Jon A. Krosnick, LinChiat Chang, Harold S. Javitz, Matthew S. Levendusky, Alberto Simpser, and Rui Wang. 2011. "Comparing the Accuracy of RDD Telephone Surveys and Internet Surveys Conducted with Probability and Non-Probability Samples." Public Opinion Quarterly 75(4): 709-47.

Zhao, Junzhou, Pinghui Wang, Jing Tao, Xiaobo Ma, and Xiaohong Guan. 2013. "A Peep on the Interplays between Online Video Websites and Online Social Networks." ariXiv: 1305.4018 .

Zimdars, Melissa. 2016. "False, Misleading, Clickbait-y, and Satirical 'News' Sources." http:/ /d279m997dpfwgl.cloudfront.net/ wp/2016/11/Resource-False-Misleading-Clickbaity-and-Satirical-\%E2\% 80\%9CNews \%E2\%80\%9DSources-1.pdf. 
